\title{
Dampak Pusaran Arus Globalisasi Terhadap Bahasa Arab
}

\author{
Akmal Fajri. \\ Akmalfajri11@gmail.com, Bahasa dan Sastra Arab, Fakultas Adab dan Ilmu Budaya - UIN Sunan \\ Kalijaga
}

\begin{abstract}
Abstrak
Globalisasi yang terjadi memberikan dampak yang besar dalam kehidupan manusia. Hal ini juga tidak lepas dari perkembangan teknologi dan informasi dari negara-negara Eropa dan Amerika yang memberikan pengaruh besar bagi negara Timur Tengah. Dampak dari globalisasi di antaranya dengan kemajuan teknologi dan komunikasi antar sosial masyarkat juga mempengaruhi terhadap budaya Arab itu sendiri, dan salah satu dari budaya Arab adalah bahasa Arab. Bahasa Arab yang merupakan indentitas dari bangsa Arab dan juga merupakan bahasa penting dalam Agama Islam. Mengalami dampak dari globalisasi yang menjadikan bahasa Arab mulai tersingkirkan dan tergerus oleh zaman. Dampak dari globalisasi serta faktor-faktornya menjadi fokus penting dalam pembahasan yang akan dibahas dalam makalah ini. Masalah-masalah yang dihadapi oleh bahasa Arab di era yang penuh dengan kemajuan teknologi dan zaman Globalisasi ini, dimana bahasa Inggris yang menjadi bahasa internasional juga akan dibahas dalam makalah ini. Metode yang dilakukan dalam penelitian ini adalah metode kuantitaif dengan cara analisi diskriptif, dan kajian pustaka terhadap bahan-bahan dari jurnal ilmiah dan buku-buku yang membahasa serta mengkupas tentang globalisasi dan dampak terhadap bahasa Arab tersebut.
\end{abstract}

Kata Kunci: Dampak Pusaran, Globalisasi, Bahasa Arab

\section{A. Pendahuluan}

Bahasa Arab merupakan bahasa yang masih bertahan dan mendunia, serta memiliki kesejajaran dengan bahasa Inggris dan Prancis sampai saat ini. Hal ini terlihat sebagaimana bahasa Arab di akui sebagai bahasa internasional dan digunakan sebagai salah satu bahasa resmi diplomasi di forum PBB. Bahkan beberapa negara non Arab mengakui bahasa Arab di negaranya serta mengapresiasikan berupa adanya tulisan-tulisan berbahasa Arab di berbagai tempat umum.

Menurut koentjoroningrat bahasa merupakan salah saru unsur budaya universal yang memiliki peran sangat penting. Tanpa adanya bahasa, sistem pengetahuan, sistem pencaharian, sistem teknologi, sistem kepercayaan, sistem organisasi masyarakat dan seni di dalam satu masyarakat akan terganggu serta 'A Jamiy Jurnal Bahasa dan Sastra Arab 
tidak dapat berjalan dengan baik. ${ }^{1}$ sehingga perkembangan bahasa tidak dapat dipandang sebelah mata dan bahasa juga merupaka kunci kemajuan dan perkembangan budaya dalam suatu masyarakat.

Perkembangan budaya yang terjadi dalam suatau masyarakat belakang ini disebabakan dengan adanya globalisasi dunia. Ritzer mengungkapkan bahwa sesungguhnya setiap bangsa dan kehidupan miliaran orang di seluruh dunia sedang ditransformasikan, seringkali hal ini terjadi secara dramatis yang dilakukan oleh globalisasi. ${ }^{2}$ Ungkapan Ritzer tersebut terlihat menengaskan bahwa pengaruh globalisasi seringkali berakibat luar biasa terhadap kehidupan dan tanpa disadari akan kehadirannya.

Pengaruh dari globalisasi tidak hanya menyebabkan terjadinya transformasi pada peradaban dunia yang melalui proses modernisasi, industrialisasi, dan revolusi informasi, tapi juga menimbulakan beberapa perubahan dalam struktur kehidupan di berbagai bidang, baik dalam bidang sosial, budaya, ekonomi, politik maupun dalam bidang pendidikan. ${ }^{3}$ Hal ini tidak dapat dihindari, pengaruh globalisasi juga berdampak dalam bahasa terutama dalam bahasa Arab dimana wilayah Timur Tengah yang menjadi salah saru daya tarik dari negara-negara Eropa dan Amerika karena merupakan pusat dari sumber alam yang melimpah.

Hal ini menyebabkan terjadi pengaruh dari globalisasi yang sangat kencang dalam wilayah Arab yang salah satunya disebabkan dengan kemajuan teknologi infomasi. Dengan demikian dalam pembahasan ini penulis mengangkat permasalahan dari dampak globalisasi terhadap bahasa Arab dan faktor-faktor globalisasi dalam bahasa Arab. Hal ini menjadi pertimbangan penulis karena bahasa Arab merupakan bagaian dari budaya Arab itu sendiri. Adapaun tujuan dari pemabahasan ini yaitu dapat mengetahui dampak dari globalisasi yang terjadi terhadap bahasa Arab itu sendiri, serta mengetahui faktor-faktor globalisasi yang mempengaruhi bahasa Arab.

1 Yuangga Kurnia Yahya, Usaha Bahasa Arab dalam Menghadapi Era Globalisasi, Prosiding Konferensi Nasional Bahasa Arab III, Malang, 7 Oktober 2017, hal. 38

2 Ritzer, Geogre dan Douglas J. Goodman. Teori Sosiologi Modern, Jakrta 2004: Kencana. Hal. 587

3 Ali Mahsun, Pendidikan Islam dalam Arus Globalisasi Sebuah Kajian Deskriptif Analitis, Journal Episteme, Vol. 8, No. 2, Desember 2013, hal. 265

\section{'A Jamiy Jurnal Bahasa dan Sastra Arab}

Volume 09, No. 1, Juni 2020 ISSN: 2252-9926 (Print), ISSN: 2657-2206 (Online) 
Sedangkan metode yang penulis gunakan dalam penelitian ini, yaitu menggunakan metode penelitian kualitatif yang bersifat analisi deskriptif. Menggunakan bahan-bahan dari penelitian sebelumnya, dengan melakukan penelitian pustaka. Adapun caranya dengan mengumpulkan data-data dari bukubuku dan jurnal yang berhubungan materi tersebut, serta bahan peneliti yang meneliti dan membahas tentang globalisasi. Juga bahan sert data-data yang membahas tentang bahasa Arab itu sendiri baik perkembangan maupun kemundurannya.

\section{B. Pembahasan dan Hasil Penelitian}

\section{a. Pengertian Globalisasi}

Kehidupan manusia di seluruh dunia sedang dilanda dengan suatu fenomena yaitu globalisasi. Globalisasi dimana ia membuka setiap batasan suatu negara maupun sekat-sekat wilayah yang ada. Information technology (IT) yang berkembang melalui era globalisasi mencipatakan dunia virtual, dunia maya, hiperrealitas, yang menyebabkan ketidakjelasan antara fakta dan fiksi, atau sulit dibedakan antara keadaan yang nyata terjadi dengan keadaan yang penuh dengan tipudaya atau kebohongan. Hal ini memiliki makna bahwa dalam globalisasi batas-batas budaya yang ada menjadi kabur sehingga dapat menimbulkan persoalan identitas budaya; antara budaya asli dan budaya global di satu sisi; dan antara heterogenitas dan homogenitas di sisi lain. ${ }^{4}$

Heterogenitas yang merupakan suatu proses di mana banyak input kultur lokal dan global yang saling berinteraksi antara satu sama lain guna untuk meciptakan semacam sesuatu perpaduan yang mengarah kepada pencangkokan kultur. Sedangkan homogenitas, merupakan suatu kultur yang dilihat sebagai ekspansi transnasional dari kode dan praktik bersama. Menurut Ritzer Kencendrungan terhadap homogenitas sering diasosisikan dengan imperilaisme kultural yang merupakan bertambahnya pengaruh internasional terhadap kultur tertentu. ${ }^{5}$

Homogenitas dan heterogenitas merupakanbagian dari globalisasi yang terjadi belakangan ini. Namun demikian, Ringgs men yebutkan bahwa banyak

4 Cokorda Istri Sukrawati, Pengaruh Globalisasi Terhadap Perkembangan Kesusastraan Bali, Balai Bahasa Provinsi Bali 30 November 2015. Hal 233.

5 Ibid, 236

\section{'A Jamiy Jurnal Bahasa dan Sastra Arab}


definisi terhadap istilah globalisasi yang berbeda dari satu disiplin ilmu terhadap disiplin ilmu lainya. Akan tetapi Waters mengungkapkan bahwa banyak yang mendefinisikan globalisasi dalam bidang ekonomi, politik dan istilah-istialah budaya. ${ }^{6}$ Sehingga dalam hal ini globalisasi dapat diartikan sebagai suatu proses masuknya suatu hal ke dalam ruang lingkup dunia yang menyentuh seluruh aspek penting kehidupan. Pusat Kajian Globalisasi Regionalisasi (CSGR) Universitas Warwick, menekankan bahwa pengertian tentang globalisasi diambil dari berbagi dimensi, yaitu politik, ideologi, ekonomi dan budaya. Banyak hal yang bisa diglobalisasikan, antaranya, "goods, services, money, people, information, effects on the internasional order as wel as less tangible things such as ideas, behavioural norms and cultural practices". 7 Dalam artian bahwasnya hal yang dapat diglobalisasikan barang, jasa, uang, masyarakat, informasi, serta yang berpengaruh terhadap tatanan internasional serta hal-hal yang kurang nyata seperti gagasan, norma perilaku, dan praktik budaya.

Sehingga dari pendapat di atas terlihat sangat jelas bahwasanya globalisasi belum memiliki definisi atau pengertian yang pasti, melainkan hanya definisi kerja yang maknanya tergantung pada sudut pandang tertentu. Hal ini juga sesuai dengan kata globalisasi itu sendiri, merupakan kata yang diambil dari kata global yang bermakna universal, sehingga definisi globalisasi masih bersifat umum.

Menurut Chase Dunn Istilah globalisasi sendiri telah digunakan sejak tahun 1980-an dan awal tahun 1990-an untuk menggambarkan perubahan penting dalam integrasi ekonomi dan sosial dunia. Dengan kata lain, globalisasi menggambarkan suatu proses dimana negara, bisnis dan orang-orang lebih terhubung dan saling tergantung antara satu sama lain melalui peningkatan integrasi ekonomi dan pertukaran atau difusi budaya (terutama dari budaya barat). Hal Ini sesuai sebagaimana yang diungkapan Labonte \& Torgerson dalam Jurnalnya Interrogating Globalisation, Health and Development. ${ }^{8}$

6 Wissal Al Allaq, Arabic Language in a Globalized World: Observations From the United Arab Emirates, AWEJ, Vol 5, No. 3, 2014. Hal. 114

7 Osman Bakar, Pengaruh Globalisasi Terhadap Peradaban, Jurnal Peradaban, Universiti Malaya, Jilid 1, 2008. Hal. 6

8 Badreya Al-Ammari, Social Sciences \& Humanities The Impact of Globalisation on Society and Culture In Qatar, Journal Peranika, Desember 2016, Hal $1536 .$.

\section{'A Jamiy Jurnal Bahasa dan Sastra Arab}

Volume 09, No. 1, Juni 2020 ISSN: 2252-9926 (Print), ISSN: 2657-2206 (Online) 
Sebagai sebuah istilah globalisasi sangat mudah dikenal dan diterima oleh masyarakat seluruh dunia, sebagaimana yang telah disebutkan di atas bahwasnya globalisasi menyentuh seluruh aspek penting kehidupan sesuai dengan wacananya. Ini ditandai dengan proses perkembangan ilmu pengetahuan dan teknologi yang sangat pesat sehingga mampu untuk mengubah dunia secara mendasar. Perubahan-perubahan ini terjadi dalam tradisi dan nilai-nilai, adapun proses perubahan yang terjadi ini melibatkan suatu proses yang saling berkaitan secara komplek dari berbagai macam perubahan sosial yang benar-benar mampu untuk mengubah kehidupan suatu individu.

Perubahan sosial yang terjadi ini juga disebabkan dengan kemajuan teknologi dan meluasnya penggunaan internet dalam kehidupan sehari-hari masyarakat, hal ini menjadi beberapa karakteristik globalisasi yang paling umum. Suarez-Orozco mengukapkan bahwa dengan perkembangan ini, banyak terjadinya perubahan di berbagai dimensi seperti "sifat belajar, bekerja, berpikir, hiburan, dan pola interpersonal dalam hubungan sosial". 9 Dari pandangan di atas, maka globalisasi memiliki pengaruh besar dalam komunikasi masyarakat dengan disertai efek tertentu dalam bahasa. Sehingga efek yang ditimbulkan dari globalisasi yang berpengaruh dalam bahasa, dan menimbulkan suatu baik maupun yang buruk terhadap bahasa itu sendiri.

\section{b. Dampak Globalisasi Terhadap Bahasa Arab}

Bahasa Arab merupakan salah satu bagian yang tidak terpisahkan dengan kehidupan umat Islam. Oleh karena itu, dengan sendirinya bahasa Arab sangat penting untuk membentuk kepribadian sebagai seorang muslim. Dengan demikian, mempelajari bahasa Arab dan menguasainya menjadi suatu keperluan bagi setiap muslim. Ini membuktikan bahwasanya bahasa Arab sangat bertahan serta mendunia dan sejajar dengan bahasa Inggris dan Prancis di era globalisasi saat ini.

Terjadinya globalisasi yang ditandai dengan perkembangan pesat di dalam hal ilmu pengetahuan, teknologi, komunikasi, informasi, dan berbagai bidang lainnya. Hal ini juga mempengaruhi penyebaran budaya asing, termasuk di dalamnya bahasa. Dan bahasa Arab mengambil peran yang penting di dalam

9 Wissal Al Allaq, Arabic Language in a Globalized World: Observations From the United Arab Emirates, AWEJ, Vol 5, No. 3, 2014. Hal. 114

\section{'A Jamiy Jurnal Bahasa dan Sastra Arab}


perkembangan yang terjadi karena globalisasi, ini di tunjukkan dengan semakin pentingnya wilayah-wilayah Timur Tengah.

kawasan Timur Tengah, yang mayoritas masyarakatnya menggunakan bahasa Arab, merupakan wilayah yang memiliki pusat sumber energy, daya, dan mineral dunia. Sehingga saat ini orang-orang berargumentasi bahwa cara hidup tradisional di wilayah Timur Tengah berada di bawah serangan dari globalisasi. Serang yang disebabkan oleh globalisasi merupakan terjadi suatu perkembangan yang pesat.

Perkembangan pesat yang disebut di atas dari berbagai bidang diperlopori oleh negara-negara Eropa dan Amerika, hal ini melazimkan masuknya bahasa dan istilah-istilah asli mereka ke berbagai negara. Akibatnya, ideologi nasionalisme semakin terkikis dengan pengaruh asing. Hal ini juga berdampak terhadap budaya negara tersebut sehingga menimbulkan konflik budaya. Crawford berpendapat bahwa ada dua aspek dari proses globalisasi yang dapat memicu secara singnifika terhadap konflik budaya, yaitu imigrasi dan perdagangan. ${ }^{10}$

Perdagangan yang meluas serta kebutuahan terhadap barang yang diperdagangkan ini berdampak terhadap suatu negara. Sedangkan imgirasi memicu homogenitas suatu negara serta dapat memicu heterogenitas sosial hal ini menimbulkan konflik indentitas. Konflik indentitas ini juga berdampak terhadap bahasa Arab. Sehingga penggunaan bahasa Arab di dunia teknologi dan akademik dianggap menjadi sebagai sebuah kemunduran dan ketinggalan zaman. $^{11}$

Sebagai kawasan bisnis yang sangat terbuka serta menjanjikan peluang dan prospek yang sangat cerah. Timur Tengah menjadi primadona baru yang sedang diperebutkan serta merebut perhatian banyak kalang di dunia. Hal ini juga ditandai dengan semakin banyaknya lembaga dan perusahana non Arab yang berdatangan serta membuka kantor di negara-negara Timur Tengah. ${ }^{12}$ Dengan kedatangan itu, menyadari bahwa bahasa Arab bukan hanya menjadi prioritas utama melainkan juga terhadap bahasa Inggris.

10 Badreya Al-Ammari, Social Sciences \& Humanities The Impact of Globalisation on Society and Culture In Qatar, Journal Peranika, Desember 2016, Hal 1538.

11 Yuangga Kurnia Yahya, Usaha Bahasa Arab dalam Menghadapi Era Globalisasi, Prosiding Konferensi Nasional Bahasa Arab III, Malang, 7 Oktober 2017, hal. 40.

12 Ubaid Ridlo, Bahasa Arab dalam Pusaran Arus Globalisasi: Antara Pesismisme dan Optimisme, Jurnal Ahya’ Al-Arbiyah, Vol 1, No. 2, 2010, hal. 216.

\section{'A Jamiy Jurnal Bahasa dan Sastra Arab}

Volume 09, No. 1, Juni 2020 ISSN: 2252-9926 (Print), ISSN: 2657-2206 (Online) 
Dengan demikian bahasa Inggris digunakan sebagai bahasa lingua franca, hal ini disebabkan karena bahasa Inggris jauh lebih banyak digunakan di seluruh dunia. Crystal berpendapat bahwa alasan utama bahasa seperti bahasa Inggris menjadi bahasa internasional adalah kekuatan politik yang dimiliki oleh rakyatnya untuk berbicara dalam bahasa Inggris. Sepanjang sejarah, bahasa Inggris menjadi bahasa politik dan ekonomi yang mendominasi dunia. ${ }^{13}$

Ostler berpendapat Lingua franca adalah bahasa yang digunakan sebagai kenyamanan dalam berkomunikasi dengan negara lain untuk mengatasi hambatan berbahasa yang telah menjadi kendala utama dalam komunikasi internasional. Sehingga lingua franca Ini tidak memerlukan untuk dipelajari sebagai bahasa ibu, melainkan dipelajari dan digunakan sebagai sarana untuk memfasilitasi diri dalam komunikasi. ${ }^{14}$

Selain dari permasalahan di atas, globalisasi juga mengakibatkan budaya konsumtif yang tinggi di kalangan Negara Arab. Ditambah lagi dengan ledakan informasi, yang secara sadar maupun tidak. Dalam hal ini mau atau tidak mau, bahasa Inggris mulai merambat ke dalam sistem-sistem sosial di kalangan Arab itu sendiri. Keadaan ini diperparah dengan adanya gerakan kolonialisme Barat di berbagai negara Arab, serta menginvansi berbagai segi kehidupan, termasuk perkembangan pemikiran dan ilmu pengetahuan. ${ }^{15}$

Permasalahan tersebut diperkuat dengan penyebaran penggunaan bahasa non-Arab, serta banyaknya istilah asing yang tidak tersedia di dalam kosakata bahasa Arab itu sendiri. At-Taujiry menyebutkan penyebaran juga terjadi di berbagai dialek (lahjah) yang semakin kompleks, hingga semakin minimnya kepedulian terhadap penggunaan ragam bahasa fuscha dalam forum resmi. ${ }^{16}$ Ini terlihat di dalam bidang pendidikan misalnya, banyak sekolah-sekolah di Timur Tengah menggunakan buku yang berbahasa Inggris, terutama dalam mata pelajaran eksakta seperti: Kimia, Fisika, Matematika dan Biologi. Begitu juga dalam dunia teknologi, masuknya penggunanan kosa kata asing yang tidak bisa dibendung.

13 Wissal Al Allaq, Arabic Language in a Globalized World: Observations from the United Arab Emirates, AWEJ, Vol 5, No. 3, 2014. Hal. 115

14 Ibid, 115

15 Yuangga Kurnia Yahya, Usaha Bahasa Arab dalam Menghadapi Era Globalisasi, Prosiding Konferensi Nasional Bahasa Arab III, Malang, 7 Oktober 2017, hal. 40.

16 Ibid, 41

\section{'A Jamiy Jurnal Bahasa dan Sastra Arab}


Sehingga bahasa Arab secara pelan tapi pasti mulai tergusur oleh bahasa Inggris. Dengan pola hidup dan kolonialisasi barat, dalam waktu yang sama terjadinya kampanye besar-besar terhadap globalisasi yang menyebarkan dan menjadikan bahasa Inggris sebagai bahasa yang paling kompatibel dengan kemajuan teknologi di zaman ini. Selain itu juga ada upaya penggantian huruf Arab dengan Latin. Farid al-Anshari menambahkan bahwa adanya agenda neokolonialisasi globalisme yang dilancarkan Barat terhadap dunia Islam dewasa ini, dengan dimaksudkan untuk "membunuh karakter dan indentitas budaya", terutama Arab. ${ }^{17}$

Menurut Mansur Hal ini terlihat di mana program tayang televisi di dunia Arab sudah banyak dipengaruhi dengan gaya dan pola hidup Barat sekuler dan materialistik. Akibatnya, minat dan motivasi para masyarakat dan pemuda untuk mempelajari bahasa Arab secara serius menjadi menurun. ${ }^{18} \mathrm{Hal}$ demikian juga terlihat di berbagai siaran langsung olah raga di dunia Arab terutama sepakbola, yang disiarkan dari Barat (liga Inggris, Spanyol, Italia, Prancis, atau belanda) banyak menggunakan bahasa Inggris.

\section{c. Faktor-Faktor Globalisasi Terhadap Bahasa Arab}

Bahasa Arab di negara-negara Timur Tengah seperti, Arab Saudi, Mesir, Syiria, Iraq, Yordania, Qatar, dan lain-lainnya, dapat dibedakan menjadi dua ragam bahasa, yaitu: Bahasa Arab fuscha dan bahasa Arab ammiyah. Kedua bahasa ini digunakan dalam konteks dan nuansa yang berbeda pula.

Bahasa Arab fuscha, biasanya digunakan dalam forum resmi seperti acara kenegaraan, ilmiah, akademi, jurnalistik, dan termasuk juga dalam khutbah. Sedangkan bahasa ammiyah, digunakan dalam komunikasi yang tidak resmi, interpersonal, dan dalam interaksi sosial di berbagai tempat misalnya: rumah, kantor, bandara, dan di tempat lainnya. ${ }^{19}$

Magin melaporkan tingkat kebutaan huruf antara 10\% dan 60\% dari populasi orang dewasa di negara-negara Arab, populasi kebutaan huruf ini juga diikuti dengan tidak dapatnya pengunaan dalam interaksi sehari-hari untuk

17 Ubaid Ridlo, Bahasa Arab dalam Pusaran Arus Globalisasi: Antara Pesismisme dan Optimisme, Jurnal Ahya' Al-Arbiyah, Vol 1, No. 2, 2010, hal. 220

18 Ibid, 220

19 Ubaid Ridlo, Bahasa Arab dalam Pusaran Arus Globalisasi: Antara Pesismisme dan Optimisme, Jurnal Ahya' Al-Arbiyah, Vol 1, No. 2, 2010, hal. 219

\section{'A Jamiy Jurnal Bahasa dan Sastra Arab}

Volume 09, No. 1, Juni 2020 ISSN: 2252-9926 (Print), ISSN: 2657-2206 (Online) 
berbicara bahasa Arab standar (fuscha), akan tetapi bahasa Arab standar tersebut hanya sebagian besar digunakan di dalam ruang kelas yang terbatas. ${ }^{20}$

Kurangnya kepedulian bangsa Arab dalam penggunaan bahasa Arab fuscha di dalam forum resmi yang diselenggarakan, kondisi ini membuat bahasa Arab semakin termarjinalkan di era globalisasi. Dan hal ini menyebabkan kemunduran terbesar bagi bangsa dan kebudayaan Arab. Selain itu, adanya upaya lain yang ingin diterapkan dan disebarluaskan di kalangan masyarakat Arab, yaitu mempopulerkan penggunan bahasa Arab kolokial (dialek lokal) serta mengesampingkan penggunaan bahasa Arab fuscha. ${ }^{21}$

Menurut Prof. Dr. Abdul Karim Khalifah, Yang Merupakan ketua Majma' Lughah Yordania, di dalam bukanya "al-Lughah al-'Arabiyyah 'ala madariji'l Qarni'l Wahid wa'l 'Isyrin', menyebutkan dan merangkum masalah-masalah yang dihadapi bahasa Arab di era Modern ini ke dalam beberapa poin sebagai berikut $^{22}$ :

1) Pemakaian bahasa Ammiyah dalam tulisan-tulisan resmi maupun pada pembacaan berita, penulisan jurnal, majalah, pengumuman, dan lain-lain. Mendiglosiakan atau meragamkan bahasa Arab disamping mengadung keunikan, juga memiliki resiko yang besar dari sisi lain. Seperti halnya banyak kosakata dan kaidah yang berlainan antara satusama lain yang membuat kebingungan bagi para penuturnya. Keadaan ini juga diperparah dengan keinginan beberapa kelompok untuk menjadikan ragam Ammiyah sebagai ragam resmi dan menggantikan alfabet Arab dengan alfabet Latin untuk mensejajarkan diri dengan bahasa Latin.

2) Penggunanan bahasa asing pada publikasi tulisan dan hasil penelitian di beberapa perguruan tinggi negeri serta dalam pendidikan sekolah-sekolah dasar sehingga menggeserkan kedudukan bahasa Arab resmi (fuscha). Adapun mayoritas perguruan tinggi di Arab sebelah Timur menggunakan bahasa Inggris sebagai pengantar ilmu kedokteran, arsitektur, teknik dan

20 Rahma Ibrahim Al-Mahrooqi, Denman, C. J., Tausiff Sultana, Factor Contributing to the Survival of Standard Arabic in the Arab World: An Exploratory Study. Journal Pertanika, Social Sciences \& Humanities, September 2016. Hal.1179

21 Ibid, 216

22 Khalifah, Abdul Karim, al-Lughah al- 'Arabiyyah 'ala Madariji'l Qarni'l Wahid wa'l 'Isyrin, Amman: Daar al-Gharb al-Islamy, 2003, hal. 85-89.

\section{'A Jamiy Jurnal Bahasa dan Sastra Arab}


berbagai disiplin ilmu lainnya, dan di sebelah Barat menggunakan bahasa Prancis sebagai pengatar ilmu-ilmu tersebut.

3) Adanya klaim-klaim tentang sulitnya belajar bahasa Arab. Baik dalam menghafalkan kaidah-kaidah bahasa Arab fuscha maupun ammiyah hal ini membuat penuturnya merasa kesulitan dalam menggunakannya sebagai bahasa teknologi, komunikasi dan pengetahuan umum.

4) Adanya klaim bahwa bahasa Arab merupakan bahasa agama Islam dan bahasa al-Qur'an sehingga bahasa Arab bersifat suci dan tidak menerima ada pembaharuan dan modernisasi dalam istilah dan kaidahnya.

5) Dalam penerjemahan bahasa Arab menggunakan 'Google Translate'. Penggunanan teknologi modern sangat membatu. Tetapi, jika aplikasi yang digunakan dalam teknologi tidak mendukung dengan program bahasa Arab yang baik, seperti cara penulisan dan huruf, maka teknologi tersebut akan menjadi ancaman untuk bahasa Arab sendiri, karena aplikasi tersebut diprogramkan untuk melayani bahasa lain yang berbeda dari bahasa Arab baik secara tulisan, huruf, dan gramatikalnya. Dengan demikian, penggunaan 'Google Translate' menjadi tidak berguna untuk bahasa Arab serta menjadi sumber masalah karena hasil dari penerjemahan tidak sesuai dengan gramatikal Arab itu sendiri.

Masalah-masalah di atas memperlihatkan dengan jelas tentang minimnya penggunaan bahasa Arab itu sendiri di lingkungan masyarakat Arab. Hal ini menyebabkan bahasa Arab menjadi bahasa yang tergerus dalam zaman teknologi pada era globalisasi ini. Faktor kemunculan internet juga menjadikan adanya perubahan sosial dalam masyarakta Arab itu sendiri, yang kontribusi bahasa Inggris lebih dominan dalam istilah-istilah internet hal ini menjadi dampak peningkataannya multibahasa.

Perluasaan penggunaan bahasa Inggris di seluruh dunia dan sering digunakan dalam komunikasi telah menimbulkan ketakutan terhadapa budaya dan bahasa setempat dikarenakan hal ini dapat terancamnya bahasa setempat oleh bahasa Inggris. Sinno menyebutkan bahasa Inggris telah menjadi bahasa Komunikasi yang dominan di dunia. ${ }^{23}$ Penggunaan bahasa Inggris dalam berbagai

23 Rahma Ibrahim Al-Mahrooqi, Denman, C. J., Tausiff Sultana, Factor Contributing to the Survival of Standard Arabic in the Arab World: An Exploratory Study. Journal Pertanika, Social Sciences \& Humanities, September 2016. Hal. 1178

\section{'A Jamiy Jurnal Bahasa dan Sastra Arab}


konteks komunikasi terhadap orang-orang yang bahasa ibunya bukan bahasa Inggris.

Bahasa Inggris sendiri di dalam era globalisasi telah menjadi bahasa pergaulan internasional dan bahasa ilmu pengetahuan. Penggunaan bahasa Inggris sebagai alat komunikasi yang telah diterima secara global mempertegas perannya bahasa Inggris sebagai bahasa Internasional atau menjadi lingua franca di beberapa negara termasuk wilayah Timur Tengah itu sendiri. Merambatnya bahasa Inggris yang berkelanjutan pada ranah penggunaan bahasa yang bergengsi dalam bisnis, perdagangan, dan akademisi yang sekarang ini didukung oleh komunikasi online, dapat dipandang sebagai ancaman terhadap bahasa dan nilainilai nasional. ${ }^{24}$

\section{Kesimpulan}

Perkembangan teknologi yang diciptkan dari negara-negara Eropa dan Amerika menyebakan pengaruh negara terhadap politik dan kekuatan negara tersebut sang didominasi yang negara tersebut berbahasa Inggris. Sehingga terjadi lingua franca pada negara Timur Tengah yang bahasanya merupakan bahasa Arab. Wilayah Timur Tengah yang menjadi primadona karena sumber alam yang melimpah menyebabkan terjadi hubungan bisnis dengan negara non Arab. Hal ini menjadikan bahasa Arab tidak hanya sebagai bahasa yang utama melainkan bahasa Inggris juga menjadi bahasa penting. Sehingga di lingkungan wilayah Arab tidak lagi menggunakan bahasa Arab resmi atau bahasa fuscha dalam forum resmi kenegaraan, penulisan jurnalistik dan tulisan ilmiah lainnya. Ini menyebakan bahasa Arab menjadi tersingkirkan serta di sekolah-sekolah dan universitas juga telah menggunakan bahasa Inggris dan Prancis dalam penggatar ilmu pendidikan dan buku-buku pelajaran. Serta ada beberapa faktor lain seperti klaim atas sulitnya mempelajari bahasa Arab serta bahasa Arab yang merupakan bahasa agama Islam dan bahasa al-Qur'an yang menjadikan bahasa Arab itu suci. Dengan demikian tidak menerima ada pembaharuan dan modernisasi dalam bahasa Arab. Hal ini membuat penutur kesulitan dalam menggunakan bahasa Arab dalam bahasa teknologi, komunikasi dan ilmu pengetahuan.

24 Mark Warschauer, dkk. Language Choice Online: Globalization and Identity In Egypt, Journal of Computer-Mediated Communication, Vol. \&, Issue 4, 1 July 2002.

\section{'A Jamiy Jurnal Bahasa dan Sastra Arab}




\section{Daftar Pustaka}

Ritzer, Geogre dan Douglas J. Goodman. Teori Sosiologi Modern, Jakrta 2004: Kencana.

Ali Mahsun, Pendidikan Islam dalam Arus Globalisasi Sebuah Kajian Deskriptif Analitis, Journal Episteme, Vol. 8, No. 2, 2013.

Badreya Al-Ammari, Social Sciences \& Humanities the Impact of Globalisation on Society and Culture in Qatar, Journal Peranika, Desember 2016.

Cokorda Istri Sukrawati, Pengaruh Globalisasi Terhadap Perkembangan Kesusastraan Bali, Balai Bahasa Provinsi Bali 30 November 2015.

Khalifah, Abdul Karim, al-Lughah al-'Arabiyyah 'ala Madariji'l Qarni'l Wahid wa'l 'Isyrin, Amman: Daar al-Gharb al-Islamy, 2003.

Mark Warschauer, dkk. Language Choice Online: Globalization and Identity in Egypt, Journal of Computer-Mediated Communication, Vol. \&, Issue 4, 1 July 2002.

Osman Bakar, Pengaruh Globalisasi Terhadap Peradaban, Jurnal Peradaban, Universiti Malaya, Jilid 1, 2008.

Rahma Ibrahim Al-Mahrooqi, Denman, C. J., Tausiff Sultana, Factor Contributing to the Survival of Standard Arabic in the Arab World: An Exploratory Study. Journal Pertanika, Social Sciences \& Humanities, September 2016.

Ubaid Ridlo, Bahasa Arab dalam Pusaran Arus Globalisasi: Antara Pesismisme dan Optimisme, Jurnal Ahya' Al-Arbiyah, Vol 1, No. 2, 2010.

Wissal Al Allaq, Arabic Language in a Globalized World: Observations from the United Arab Emirates, AWEJ, Vol 5, No. 3, 2014.

Yuangga Kurnia Yahya, Usaha Bahasa Arab dalam Menghadapi Era Globalisasi, Prosiding Konferensi Nasional Bahasa Arab III, Malang, 7 Oktober 2017. 